\title{
BMJ Open Qualitative situational analysis of palliative care for adolescents with cancer and HIV in South Africa: healthcare worker perceptions
}

\author{
Nothando Ngwenya, ${ }^{1}$ Julia Ambler, ${ }^{2}$ Moherndran Archary ${ }^{3}$
}

To cite: Ngwenya N, Ambler J, Archary M. Qualitative situational analysis of palliative care for adolescents with cancer and HIV in South Africa: healthcare worker perceptions. BMJ Open 2019;9:e023225. doi:10.1136/ bmjopen-2018-023225

- Prepublication history for this paper is available online. To view these files, please visit the journal online (http://dx.doi. org/10.1136/bmjopen-2018023225).

Received 4 April 2018

Revised 25 October 2018

Accepted 8 November 2018

A) Check for updates

(C) Author(s) (or their employer(s)) 2019. Re-use permitted under CC BY-NC. No commercial re-use. See rights and permissions. Published by BMJ.

${ }^{1}$ Africa Health Research Institute KwaZulu-Natal, South Africa ${ }^{2}$ Umduduzi Hospice Care for Children, Durban, South Africa

${ }^{3}$ Paediatric Infectious Diseases Unit, King Edward VIII Hospital University of KwaZulu-Natal, Durban, South Africa

Correspondence to Dr Nothando Ngwenya; nngwenya@ahri.org

\section{ABSTRACT}

Objectives The unmet palliative care need is intensified in resource-limited countries where there is inequitable access to healthcare and adolescents and young adults (AYA) fall between the cracks of paediatric and adult services. We aimed to examine palliative care for AYA with cancer and/or HIV in South Africa.

Design Individual and small group interviews using process mapping.

Setting Data were collected between November 2016 and March 2017 with staff from government hospitals, hospices and clinics from three provinces of South Africa. Participants Health and social care professionals $(n=30)$ (eg, physicians, nurses, social workers, psychologists) from KwaZulu-Natal, Western Cape and Gauteng provinces. Methods In this qualitative situational analysis study, participants were recruited to interviews and process mapping used to try and identify palliative care pathways of AYA with palliative care needs. We developed a thematic framework using a deductive approach to analyse the interview data.

Results Palliative care pathways were not easily identifiable, ambiguous and varied and participants reported on their experiences and perceptions of service provision. Participants expressed that resource challenges limited the service provision. A need for nurse prescribing of pain relief at community level was mentioned as AYA are reluctant to use hospitals and clinics. Lack of (1) palliative care education among professionals, (2) public awareness and (3) adolescent-specific care posed a challenge to service provision.

Conclusions The changing burden of HIV and increase in cancer prevalence calls for integration of palliative care in mainstream health services. Despite good policies, the pragmatic aspect of training professionals will influence a change in practice. The main task will be to absorb palliative care philosophy and practice at all levels of care to avoid overburdening the care system and to integrate it in community care programmes.

\section{INTRODUCTION}

It has been over 10 years since Harding and Higginson's ${ }^{1}$ seminal review of palliative care in sub-Saharan Africa (SSA); however, progress with provision of care has been slow. ${ }^{2}$ Although Rhee and colleagues' ${ }^{3}$ review

\section{Strengths and limitations of this study}

This is the first study to conduct a situational analysis of palliative care pathways for adolescents and young adults in a rural setting in South Africa.

- Perspectives from a wide range of stakeholders across health and social care within the public and non-governmental sectors were included.

- The findings provide depth of insight into the contextual relevance of understanding palliative care when resources are limited.

- A limitation is that young people's perspectives were not included in this study.

indicates a growth in palliative care in Africa over the last 12 years, availability of services is variable and inconsistent. Palliative services are largely provided by non-governmental organisations (NGOs), which can limit accessibility and sustainability ${ }^{4}$ and have a low priority compared with curative service.

The need for palliative care in HIV has been well established with research showing that patients on highly active antiretroviral therapy experienced high symptom burden, comorbidities and lifelong care management. ${ }^{5}{ }^{6}$ Optimal management of HIV requires a combined effort of treatment and long-term care as proposed by the Joint United Nations Pogramme on HIV/AIDS (UNAIDS) 90-90-90 targets. $^{7}$ A comprehensive integrated approach that combines acute and palliative services is necessary for HIV and non-communicable diseases such as cancer, which are an urgent public health concern in Africa. The past three decades has seen attention given to HIV/AIDS, leading to the wrong perception that cancer is not a major problem.

Having a life-limiting or life-threatening condition at the developmental stage of adolescence can be challenging with substantial life adaptations needed. ${ }^{9} 10$ Poor adherence 
and associated health risks such as opportunistic infections may impact on their illness consequently leading to poor outcomes. ${ }^{11} \mathrm{~A}$ considerable amount of literature has reported that healthcare professionals find caring for adolescents and young adults (AYA) challenging and lack the communication skills/strategies required. ${ }^{9}{ }^{12}$ Adolescents with palliative care needs are different from adults: specific challenges include multigeneration involvement (parents, adolescent, grandparents), impact on siblings, separation from peers, self-esteem, interaction with parents and their involvement in decision-making which may cause moral distress and discomfort for the care provider. ${ }^{13}$

Following the World Health Assembly's palliative care resolution in 2014, there has been a steady growth of palliative care services and research in Africa. This paper has used WHO's definition of palliative care which states that, 'palliative care is an approach that improves the quality of life of patients and their families facing the problem associated with life-threatening illness, through the prevention and relief of suffering by means of early identification and impeccable assessment and treatment of pain and other problems, physical, psychosocial and spiritual. ${ }^{, 4}$ During the study, in August 2017, South Africa published the National Framework and Strategy for Palliative Care, stating that 'Palliative care should be available to all patients as needed from birth until death and should be accessible at all levels of the healthcare service.' This study contributes to the evidence examining palliative care service provision for AYA.

\section{METHODS}

\section{Design and setting}

A qualitative approach was employed for this formative study to investigate the palliative care pathways for AYA with cancer and HIV in urban and rural KwaZulu-Natal (KZN), South Africa. However, from the interaction with participants, it was evident that at the time that the study was conducted, there were no national palliative care pathways or processes to guide professionals in the care of AYA, and instead participants shared about service provision according to their perspectives. We interviewed social and healthcare professionals involved in the care of AYA in all care settings including NGOs. Qualitative interviews were most appropriate for this study as they give respondents the opportunity to explore themes presented by the questions. ${ }^{15}$ As the conception of this project was about palliative care pathways, process mapping ${ }^{16}$ (a central part of integrated care pathway development) was used to allow participants to plot their individual part in the patient journey. This was not successful as participants indicated that there was no specific palliative care referral pathway let alone for AYA. Some also shared that they plotted an ideal process map rather than one that portrayed the reality of what happened. In addition, we recruited professionals from two other provinces that together represent the most populous provinces in South
Africa, Gauteng and Western Cape, to understand the level of referrals and service provision outside of KZN. Gauteng is also the only province with a government palliative care centre.

\section{Recruitment and sampling \\ Participants}

Participants were purposely sampled to represent a wide range of professionals from different care settings. The recruitment followed the clinical referral pathways beginning from the primary healthcare clinic. Africa Health Research Institute (AHRI) identified a local clinic, and their operational manager helped find a willing staff member to participate in the study. During the interview, the participant was asked to propose a colleague from a referral hospital. The researchers approached the proposed professional to participate in the study. If a participant could not identify a colleague from a referring hospital, a contact person at that hospital was identified that was known to the researchers. Other participants were recruited through a 'snowball technique' including professionals based in NGOs. All participants were involved in the care of AYA either in the paediatric or adult services.

\section{Patient and public involvement}

The development of the research question was informed by patient's priorities and experiences in a separate project with AYA with cancer. The current project was informed by the researcher's experience working with AYA with terminal cancer in the UK and therefore sought to explore services in a resource-limited setting. This previous experience working with AYA with cancer could have influenced the research through assumptions made based on knowledge of palliative care services in oncology in the UK compared with South Africa. There were no patients involved in the recruitment or conduct of the study as this is a situational analysis from care providers' perspectives. Care providers including advisors from national palliative care associations were involved in initial discussions to inform the context of service provision in South Africa. We liaised with and sought advice from the AHRI Community Advisory Board (CAB) on the conduct of the study within the local community as well as discussions with local chiefs through community dialogues. Results will be communicated through community roadshows which will give people the opportunity to engage and interact with the findings.

\section{Data collection}

Data for this study were collected from November 2016 to March 2017 through face-to-face, semistructured interviews that lasted an average of $65 \mathrm{~min}$. All interviews took place in each participant's practice or place of work. We approached the participants by telephone or email, and the primary researcher (NN) explained the study aims and methods. Written informed consent was taken from each participant. The information sheet indicated 
that the study sought opinions and experiences from professionals regardless of their knowledge or previous interaction with palliative care services. Interviews were conducted until a point where data saturation was reached ${ }^{17}$ with a total of 30 health and social care professionals. Governance permission from the provincial and district Department of Health offices where the research was being conducted was granted.

A semistructured topic guide was developed informed by literature and local palliative care practices. The topic began with general questions about the health professional's work setting; their general experiences with care and treatment of AYA; their sources of referral for AYA with cancer and HIV; and then specifically on palliative care services and their opinions and views on provision. The interviewer pursued themes as they arose and used this approach to seek clarification but did not contribute with definitions of terminologies. We explored and evaluated respondents' meaning of palliative care without giving them WHO definition that the study is using.

During the interview, participants were asked to construct a model of the patient journey and their specialty (cancer or HIV) treatment processes. An activity diagram was developed from this information during the interview to model the care pathways of the patient journey. The model was verified and modified at each interview with a final validation by the last interviewee at each province who was usually a practitioner at the tertiary hospital. Although the initial use of process mapping was to identify palliative care pathways, the method became more useful in probing and engaging with participants than its intended use. The interviews were audiotaped with the permission of the respondents. Four participants asked to be interviewed together as a pair (two pairs of two). Two other participants requested not be taped, the interview setting for another four did not make it possible to record and, in these cases, notes were taken during the interview. The interviews were conducted in English and transcribed verbatim by an external professional organisation used by the Institute. Out of the 30 interviews, four were recorded in IsiZulu, transcribed and translated into English by a research assistant in the Institute whose role involves transcribing and translating for various projects. These transcripts were quality checked by NN for translation accuracy

\section{Analysis}

Data analysis was based on a constant comparison approach $^{15}$ and iterative process by continually looking for similarity and differences in the data across transcripts. We followed the constructive grounded theory approach of: open coding, which is the initial examining of data to identify words or phrases of interest and importance based on the questions; axial coding, which groups the codes according to their relational characteristics; and, finally, by analysing the categories, we selected key overarching concepts. ${ }^{18}$ For the interviews that were not recorded, the interviewer audio-recorded their notes immediately after, so as not to lose any details, and so these data were not recorded verbatim. These recordings were then transcribed. These notes were used to rephrase and modify the topic guide. The same analytical process was applied to summaries of the interviews that were not audio-recorded with the awareness that these specific summaries were not verbatim. These emerging themes were also used as probes during the next interview conducted as a way of validating the data and interpretations made and shared with all authors. NN subsequently coded the remaining transcripts while also checking interpretations with the existing data. During the coding process, the seminar series at the Institute were used for data validation with emerging themes shared with the group and feedback given which informed the development of final themes. The constant comparison approach helped in identifying our saturation point as we were no longer getting distinctly new themes in relation to the referral pathways. All data were analysed with qualitative research software (NVivo V.11).

\section{RESULTS}

\section{Respondent characteristics}

We contacted health and social care professionals that were known to the researchers (MA, JA) as well as individuals we were referred to by other interviewees. As the data collection and analysis processes ran concurrently, we tried to contact 35 professionals, we did not get a response from 2, another 2 could not be contacted and 1 declined leaving a total of 30 participants (see table 1). Most participants were women, and we did not record participant's age. Work experience and professions varied with 28 having more than 5 years' experience in their profession and 2 junior doctors in their first year in practice.

\section{FINDINGS}

Four overarching domains of interest were identified that provided insight into palliative care service provision for AYA in a resource-limited setting: role of palliative care, care continuity in the community, misconceptions of palliative care and AYA are overlooked.

\section{Role of palliative care}

Although awareness and the importance of palliative care for all medical conditions was acknowledged, some participants questioned its appropriateness in a place with high levels of poverty and scarce resources. Participants expressed that palliative care could only be delivered after physiological needs were met:

Here in this area where we work most of the problems are social ... palliative care you can do it anywhere, but it's just made so much easier if a person's basic needs are met, then you can do the proper palliative care [Rural based HM1]

Participants clearly articulated the difference between how palliative care is often defined and the services they 
Table 1 Characteristics of health professionals interviewed about the palliative care pathways for Adolescents and Young Adults (AYA).

\begin{tabular}{|c|c|c|}
\hline Province & Setting & Participants and identifiers \\
\hline \multirow[t]{6}{*}{ KwaZulu- Natal } & Community & Two female community caregivers [CCG1, CCG2], one male family physician [FP1] \\
\hline & Primary care clinic & Two female operational managers [OM1, OM2], one female nurse [SN1] \\
\hline & District hospital & $\begin{array}{l}\text { Two male junior physicians, one in accident and emergency, one in paediatrics [JP1, } \\
\text { JP2], two female social workers [SW1, SW2] }\end{array}$ \\
\hline & Provincial hospital & $\begin{array}{l}\text { One female HIV physician with a focus on adolescents [InDP1], one female } \\
\text { paediatrician [Ped1] one male HIV physician [InDP2], one female HIV care paediatrician } \\
\text { [InPed1] }\end{array}$ \\
\hline & Tertiary hospital & One female oncology physician [Onc1], one female haematology oncologist [Haem1]. \\
\hline & $\begin{array}{l}\text { Non Governmental } \\
\text { Organisations (NGO) }\end{array}$ & $\begin{array}{l}\text { One female nurse manager for HIV organisation [NM1], two social workers for cancer } \\
\text { organisation [SW3, SW4], one female senior nurse from a hospice [HSN1], one female } \\
\text { manager from a hospice [HM1]. }\end{array}$ \\
\hline Gauteng & \multicolumn{2}{|c|}{$\begin{array}{l}\text { One female NGO hospice nurse [HSN2], one female palliative care nurse from a tertiary hospital [PCN1], one } \\
\text { female paediatrician from tertiary hospital [Ped2], one female NGO psychologist [Psy1], one female NGO } \\
\text { adolescents' physician [ADP1]. }\end{array}$} \\
\hline Western Cape & \multicolumn{2}{|c|}{$\begin{array}{l}\text { One female NGO palliative care paediatrician [PCPed1], one female NGO palliative care therapist [PCT1], } \\
\text { one female NGO palliative care nurse [PCN2], one female palliative care officer [PCO1]. }\end{array}$} \\
\hline
\end{tabular}

The abbreviations are the pseudonyms used to identify speakers in the quotations of the results section.

offer based on the needs in rural SSA. In a lot of cases, patients seek assistance for basic needs such as food and shelter:

\section{People come to us for food and Department of health doesn't have food, and they say they cannot take their medication without food [Rural based SW1]}

The social workers stated that trying to focus on a patient's pain when they complain of hunger seems to be futile in addressing that patient's need and does not address the 'total care' of the patient as per the definition of palliative care.

Professionals in the rural areas expressed that they are faced with crisis management and prevention through adherence support, monitoring medication compliance and following up patients lost to the system:

Really now palliative care is more like preventive care and really it is all about trying to prevent escalation of symptoms and trying to manage chronicity for young people. [Urban based ADP1]

\section{Care continuity in the community}

The context of life in the rural parts of Africa is such that people rely on friends and neighbours with everyday life situations. Harnessing this culture according to participants would help integrate palliative care principles as whether through choice or in response to the practicalities, most people will be cared for and die at home.

when the professionals have identified that maybe nothing can be done and so now it becomes the responsibility of the family to look after the patient as well as the community. [Urban based Haem1]
Even when patients are discharged and cared for at home or some hospice services, there is a lack of pain control available to these patients as nurses are not able to prescribe pain relief and rely on volunteer doctors to do so:

And you can be a cancer patient and get maybe five Panadol or something like that, so we do have a volunteer doctor who comes once a week and then we are able to provide medication at hospice expense [Rural based HM1]

Participants in the rural hospitals stated that communities need to be equipped with skills to look after their family members. Lack of skills and confidence caused some people to leave their relative in the hospital and refuse to take them home as they know they are not able to care for them:

Lots of our patients who remain here in the hospital, their relatives refuse to accommodate them., ... they will come once the patient has died because they know that it's beyond their control and there is nothing they can do [Rural based SW2]

\section{Misconceptions of palliative care}

There are many misunderstandings of palliative care from the public as well as care professionals. Some participants expressed shared misconceptions held about palliative care. There was the view that HIV was not seen as a condition that needed palliative care due to the availability of Antiretrovirals (ARVs). Other healthcare professionals still understand palliative care to be end-of-life care. One participant described how the reticence to acknowledge and refer patients to palliative care could be linked to 
professionals feeling that they have failed or were giving up:

We fought so hard for HIV antiviral treatment in South Africa but palliative care referring a patient to palliative care as a HIV person almost was like admitting defeat. [Urban based PCPed1]

And I suppose also within the HIV setting, we don't think of it at all as needing palliative care somehow ... that's a mistake I'm sure because then we're just thinking just end-oflife care, not a holistic approach to someone with a possibly life-threatening disease. [Peri-urban InPed1]

Most of the participants acknowledged that there was a lack of palliative care education within the medical, nursing and allied healthcare professionals' curricula. It is also not practised by senior colleagues whom junior doctors emulate. Palliative care education was limited in the undergraduate training and less within practice for professional development:

The thing is it (palliative care) is taught but not focused on so it is one of the things that you read about it, you wrote a test, okay it is like family medicine out of 100 then $5 \%$ palliative and you learn it in 1 day, so it is not something that we will say is a priority it is something that you must know by the way there is palliative care. [Rural based JP1]

\section{Adolescents have been overlooked}

Participants stated that there are a lot of young people including orphaned children now coming up to adolescence with complex issues needing palliative care. Some participants explained that young people tend to be forgotten because most of the care in the health system and in hospitals is focused on adults due to the number of patients:

I think generally, obviously the adults have higher numbers and higher needs in terms of number who need to be tested and treated and everything [Urban based InDP1]

I think to some large extent adolescents have been overlooked and it's only fairly recently that they're on people's radar... they kind of got lost in-between. [NGO-based HIV Physician]

Some participants stated that the structure of the healthcare system meant that many young people go unnoticed. These young people fall through the cracks during their transitions to adult services. Young people moving into an adult ward at an early age of 12 can be distressing and overwhelming:

The biggest concern is that young people after they turn 12 years old they are treated in the same ward as the adult patients which can be very unnerving for young people. [Urban based Onc1]

Young people in hospital also have challenging needs including social and developmental aspects such as attending school. This increases the isolation they feel and are left behind by the peers which can be quite disconcerting for an adolescent:

When they are diagnosed, they spend quite a length of time and period in the hospital and they therefore miss out schooling and education. [Urban based SW3]

Participants described the complex challenges that AYA have and the challenges that they pose in caring for them. Sometimes the adult care professionals might feel that they do not have the skills to work with these young people and therefore be uncomfortable caring for an adolescent patient:

And what sometimes happens is that ... (adult services) will call us (Paediatrics department) and say, 'Please can you assist?' ..., now I think it's a question of How comfortable are the adults (adult services) in terms of looking after them? [Urban based Ped2]

\section{DISCUSSION}

An initial objective of the project was to examine the palliative care pathways for AYA with cancer or HIV. However, from the process mapping exercise, participants indicated that palliative care pathways did not exist and therefore they acted according to their own individual but professional decision in referring patients. In South Africa, the bulk of palliative care is provided by NGOs with only one government-funded palliative care facility in Soweto, Gauteng province. Resource limitations were experienced in all settings, however, more pronounced in rural areas where there is a shortage of doctors, limited access to NGOs providing palliative care and long journeys to access healthcare or specialist services. Participants described how lower level needs ${ }^{19}$ had to be fulfilled before palliative care could be provided. We argue that addressing a patient's symptoms such as pain which may be exacerbated by poverty is a component of palliative care. ${ }^{20}$

First, the current study found that there was no clear referral pathway for AYA with palliative care needs. Some professionals did not feel they were equipped to deal with these young patients, which is consistent with Thompson and colleagues, ${ }^{21}$ findings which reported that some professionals have varying skills and lack confidence in caring for young people. Second, although WHO advocates palliative care as essential in HIV care, this study found that this was not necessarily a view shared by some healthcare professionals. There are several possible explanations for this result including the misconceptions held about palliative care. Professionals in HIV care previously faced death from AIDS, and palliative care was part of an end-of-life care package. Some professionals still hold on to these traditional concepts of palliative care. This finding and its implications are consistent with previous findings,${ }^{22}$ which identified a need for palliative skills in HIV care. 
Third, there is a strong history of community-based care in Africa based on the 'ubuntu' philosophy. 'Ubuntu' is a southern African concept of values and principles of community living. The findings suggest that a community model would be more sustainable in the long run, providing continuity of care for AYA reticent to go to health facilities and help move palliative care from the clinical bedside to the village. ${ }^{23}$ Lastly, although not specific to adolescents, an important finding of this study is the major bottleneck experienced in palliative service provision due to the lack of health workers who can prescribe morphine. Using the task shift model to train nurse prescribers would assist in developing a community service and enable patients to gain faster access to pain relief medicines. ${ }^{24}{ }^{25}$ According to Brooks, ${ }^{26}$ nurse prescribers improve the efficiency of healthcare providing timely treatment which would be convenient and more practical in the community setting.

Finally, a few important limitations need to be considered. The current study only examined the views of healthcare professionals and not young people. The findings may therefore be biased towards the professionals' experiences and preferences; however, all the participants interviewed have cared for AYA in some capacity for a period of over 5 years. Though the sample size was small, it is encouraging to compare the findings to other studies in chronic care which illustrate that palliative care is not only about end-of-life care for cancer. ${ }^{27}$ We acknowledge the limitations of the analysis due to some of the interviews not being recorded verbatim and therefore relied on the interviewer's recall.

\section{CONCLUSION}

Previous research has demonstrated the effectiveness of palliative care for both cancer and HIV; however, the challenge for SSA is implementing sustainable services. Despite its exploratory nature, this study offers some insight into healthcare professionals' interpretations of palliative care service provision in the era of antiretroviral therapy in South Africa, highlighting the need to educate all health and social professionals in palliative care philosophy to provide generalist support..$^{28}$ Health Care Professionals (HCPs) are not confident in caring for AYA and the coordination and transition of their care remains a difficulty; training and support to equip professionals with the skills and confidence to care for young people could help with this process. ${ }^{29} 30$ The rehabilitative palliative long-term care of AYA living with HIV should be a part of this service working alongside active management of the disease throughout a patient's illness. ${ }^{31}$

Acknowledgements This work was conducted as part of a postdoctoral visiting fellowship award funded by the National Research Foundation in South Africa. Support of the work was given by various members of the Hospice and Palliative Care Association of South Africa who helped identify potential participants and gave more insight to policy development. We also appreciate the advice and input from the Africa Health Research Institute Community Advisory Board for guidance in working with the local community.
Contributors NN and MA developed the conceptual protocol and submitted work for ethical approval. MA, JA, and NN identified participants and introduced the study, and NN conducted data collection. All authors contributed to study design through ongoing analysis and review of data collected and contributed to the manuscript write-up. All authors have seen and approved the final version of the paper for publication.

Funding The project was funded by the National Research Foundation South African Agency for Science and Technology Advancement, Reference ECR151203156329. Funding for open access publication was through financial support provided by ViiV Healthcare's Positive Action for Adolescents Programme Grant number ITCRZF51.

Disclaimer The funding source had no direct role in the study design or interpretation of the data.

Competing interests None declared.

Patient consent Not required.

Ethics approval University of KwaZulu-Natal Research Ethics committee.

Provenance and peer review Not commissioned; externally peer reviewed.

Data sharing statement The anonymised transcripts can be made available only in a data enclave on the AHRI data repository. This process can be initiated by sending a formal request to the corresponding author and a concept sheet completed detailing the purpose of the request and data required.

Open access This is an open access article distributed in accordance with the Creative Commons Attribution Non Commercial (CC BY-NC 4.0) license, which permits others to distribute, remix, adapt, build upon this work non-commercially, and license their derivative works on different terms, provided the original work is properly cited, appropriate credit is given, any changes made indicated, and the use is non-commercial. See: http://creativecommons.org/licenses/by-nc/4.0/.

\section{REFERENCES}

1. Harding R, Higginson IJ. Palliative care in sub-Saharan Africa. Lancet 2005;365:1971-7.

2. Anderson RE, Grant L. What is the value of palliative care provision in low-resource settings? BMJ Glob Health 2017;2:e000139.

3. Rhee JY, Garralda E, Torrado C, et al. Palliative care in Africa: a scoping review from 2005-16. Lancet Oncol 2017;18:e522-e531.

4. Clark D. From margins to centre: a review of the history of palliative care in cancer. Lancet Oncol 2007;8:430-8.

5. Farrant L, Gwyther L, Dinat N, et al. Maintaining wellbeing for South Africans receiving ART: the burden of pain and symptoms is greater with longer ART exposure. S Afr Med J 2014;104:119-23.

6. Harding R, Molloy T, Easterbrook P, et al. Is antiretroviral therapy associated with symptom prevalence and burden? Int J STD AIDS 2006;17:400-5.

7. Davies M-A, Pinto J. Targeting 90-90-90 - don't leave children and adolescents behind. J Int AIDS Soc 2015;18.

8. Kimani KN, Namukwaya E, Grant L, et al. Cancer and palliative care in Africa. Eur J Cancer Care 2017;26:e12655.

9. Edwards J. A model of palliative care for the adolescent with cancer. Int J Palliat Nurs 2001;7:485-8.

10. Inglin S, Hornung R, Bergstraesser E. Palliative care for children and adolescents in Switzerland: a needs analysis across three diagnostic groups. Eur J Pediatr 2011;170:1031-8.

11. Michaud P-A, Suris JC, Viner R. The Adolescent with a Chronic Condition Epidemiology Developmental Issues and Health Care Provision. 2007 www.inis.ie (Accessed 7 August 2018).

12. Wiener L, Weaver MS, Bell CJ, et al. Threading the cloak: palliative care education for care providers of adolescents and young adults with cancer. Clin Oncol Adolesc Young Adults 2015;5:1.

13. Nayak M, Salins N. Providing palliative care for a dying teen at home: perspectives and challenges. Indian J Palliat Care 2011;17:248-50.

14. Al-Mahrezi A, Al-Mandhari Z. Palliative Care: Time for Action. Oman Med J 2016;31:161-3.

15. Ritchie J, Lewis J, McNaughton Nicholls C, et al. Qualitative Research Practice : A Guide for Social Science Students and Researchers.

16. Trebble TM, Hansi N, Hydes T, et al. Process mapping the patient journey: an introduction. BMJ 2010;341:c4078.

17. Pope C, Ziebland S, Mays N. Qualitative research in health care. Analysing qualitative data. BMJ 2000;320:114-6.

18. Mills J, Bonner A, Francis K. The Development of Constructivist Grounded Theory. Int J Qual Methods 2006;5:25-35. 
19. Maslow AH. A theory of human motivation. Psychol Rev 1943;50:370-96.

20. Zalenski RJ, Raspa R. Maslow's hierarchy of needs: a framework for achieving human potential in hospice. J Palliat Med 2006:9:1120-7.

21. Thompson K, Dyson G, Holland L, et al. An exploratory study of oncology specialists' understanding of the preferences of young people living with cancer. Soc Work Health Care 2013;52:166-90.

22. Collins K, Harding R. Improving HIV management in subSaharan Africa: how much palliative care is needed? AIDS Care 2007:19:1304-6.

23. Kellehear A. Compassionate communities: end-of-life care as everyone's responsibility. QJM 2013;106:1071-5.

24. Latter S, Courtenay M. Effectiveness of nurse prescribing: a review of the literature. J Clin Nurs 2004;13:26-32.

25. Bradley E, Nolan P. Impact of nurse prescribing: a qualitative study. $J$ Adv Nurs 2007;59:120-8.
26. Brooks N, Otway C, Rashid C, et al. The patient's view: the benefits and limitations of nurse prescribing. $\mathrm{Br} \mathrm{J}$ Community Nurs 2001;6:342-8.

27. Gwyther L, Dinat N, Mmoledi K, et al. SAMJ : South African Medical Journal = SAMT : Suid-Afrikaanse Mediese Tydskrif. South Africa: Medical Association of South Africa, 2014

28. Harding R, Selman L, Powell RA, et al. Research into palliative care in sub-Saharan Africa. Lancet Oncol 2013;14:e183-8.

29. Blum R, Smith M. Training of health professionals in adolescent health care. Study group report. J Adolesc Health Care 1988;9:S46-50.

30. Kerem NC, Hardoff D. Adolescent health care education and training: insights from Israel. Int $J$ Adolesc Med Health 2016;28:303-7.

31. Selwyn PA. Why should we care about palliative care for AIDS in the era of antiretroviral therapy? Sex Transm Infect 2005;81:2-3. 